\section{Misplaced allegations}

A s chairs of the Clinical Research Ethics Board (REB) at the University of British Columbia (UBC), we felt we should respond to the allegations made in CMA7's Holiday Review by Ian Scott and Cheryl Wilson, ${ }^{1}$ both of UBC. Although there does appear to be a correlation between forest industry activity and the paper demands of research ethics boards, we suspect that this is more association than causation.

Nonetheless, we were concerned about the issue and conducted some further research. Ethics approval was not sought, because we could not afford to make the 20 copies required by our own REB. What we found is far more disturbing than the aforementioned association. Table 1 clearly shows what appears to be a strong association between the number of copies of ethics applications required by REBs and the number of Conservative Party of Canada plus Progressive Conservative (PC) members of Parliament from each province (Table 1). We are not sure how this factor has influenced the number of copies required by REBs, but we plan to find out. We also believe that the reason the PCs are still listed (at the time of writing, in mid-January 2004) as a separate entity in the House of Commons party standings, ${ }^{2}$ despite recent reports of a merger with the Canadian Alliance, is to obscure this association.

Hence, for the foreseeable future, we plan to approve only research proposals that look into this issue. To expedite the process, we will require only 1 copy of any original research proposal that examines this disturbing trend. However, if the application comes from the Department of Family Practice at UBC, 40 copies will be required.

\section{James McCormack}

Associate Chair

Peter Loewen

Chair

Clinical Research Ethics Board

University of British Columbia

Vancouver, BC

(Not on behalf of any of the other members of the UBC Clinical Research Ethics Board.)

\section{References \\ 1. Scott I, Wilson C. Understanding the number of copies of ethics applications required by faculties of medicine. CMA7 2003;169(12):1297. \\ 2. Party standings [online]. Ottawa: House of Com- mons; 2003. Available: www.parl.gc.ca/information /about/process/house/partystandings/standings-e.htm (accessed 2004 Jan 19).}

Competing interests: Both Dr. McCormack and Dr. Loewen receive an honorarium for the work they do on the UBC Clinical Research Ethics Board.

DOI:10.1053/cmaj.1040021
[One of the authors responds:]

T $\mathrm{T}$ e appreciate the desire of James McCormack and Peter Loewen to further understand the cause of the disparate number of copies of research applications required for submission to research ethics boards at different universities, as reported in our article. ${ }^{1}$

However, we were disappointed to learn that the Clinical REB at UBC has arbitrarily singled out our group and henceforth will be demanding 40 copies of any applications from the Department of Family Practice. In response, we plan to foster collaboration by seeking formal cross-appointments to the Faculty of Pharmaceutical Sciences for all members of our department, which we hope will lead to this unfair ruling being overturned. We wish to assure readers that the fact that members of the Faculty of Pharmaceutical Sciences get to personally experiment with all the great new drugs has nothing to do with our attempt to join this group.

\section{Ian Scott}

Department of Family Practice (and, hopefully, Faculty of

Pharmaceutical Sciences)

University of British Columbia

Vancouver, BC

\section{Reference}

1. Scott I, Wilson C. Understanding the number of copies of ethics applications required by faculties of medicine. CMA7 2003;169(12):1297.

DOI:10.1053/cmaj.1040189

\section{Sample size and study interpretation}

$M$ ax Pittler and associates ${ }^{1}$ report the results of a randomized double-blind crossover trial of the effectiveness of artichoke extract in preventing alcohol-induced hangovers. However, their sample size of 15 is too small. Even though the study had a crossover design, the standard deviations (SDs) 